Ueber die Bestimmung des Schwefelgehaltes im Roheisen. Yon

\title{
Demselben. *)
}

Die bisher zur Bestimmung des Schwefelgehaltes im Roheisen in Anwendung gebrachten Methoden lassen sich wesentlich auf zwei Principien zurückführen. Sie berwhen entweder auf einer directen Oxydation des Roheisens and Fällung und Bestimmung der durch Oxydation des vorhandenen Schwefels entstandenen Schwefelsäure als Barytsalz, oder sie bezwecken zunächst die Ueberführung des vorhandenen Schwefels in Schwefelwasserstoff, durch dessen Umsetzung mit einem geeigneten löslichen Metallsalze zuerst ein unlösliches Schwefelmetall dargestellt und dieses entweder direct gewogen oder was präciser ist, nach vorgehender Oxydation desselben ein passendes schwefelsaures Salz dargestellt und aus der Menge dieses endlich der ursprüngliche Schwefelgebalt berechnet wird. Die ersteren, zu denen die von Morfit und J. Booth**) angewandte und die von J. Nicklés ****) empfohlene gehören, sind, wie das schon von E. $\mathrm{Ni}$ cholson and D. Price $\dagger$ ), daun ron G. Lippert $\dagger \dagger$ ), so wie von R. Fresenius $\dagger \dagger$ ) erörtert worden ist, und wie ich mich neuerlich wiederholt zu überzengen Gelegenheit hatte, ziemlich unzuverlässig und kaum anzuempfehlen, wäbrend letztere, welche ursprünglich von E. Nicholson und D. Price in ihrer unten genannten Abhandlung angegeben, und später von $G$. Lippert sinnreich modificirt wurde, zumal unter Beachtung der zuletzt ron R. Fresenius in seiner trefflichen Anleitung zur quantitativen chemischen Analyse angegebenen Sicherheitsmaassregeln, ohne $Z$ weifel völlig genaue Resultate erreichen lässt. Dagegen lässt sich anderseits nicht läugnen, dass eben

*) Vorgelegt in der Sitzung der k. k. Akademie der Wissenschaiten am 23. Juli 1868. Vom Verf. mitgetheilt.

**) Chem. Gaz. October 185̄3, Nr. 264, p. 388 und Nr. 265, 411.

***) Compt. rend. 55. 503.

†) Philos. Magaz. (4) XI. Nr. 71, p. 169.

†i) Fresenius Zeitschrift für analyt. Chemie II. p. 39.

十†) Fresenius Zeitschrift für analyt. Chemie II. p. 439, sowie dessen Anleitung zur quant. chem. Analyse 5. Aufl. p. 823. 
428 Gintl: Ueber die Bestimmung des Schwefelgehaltes im Roheisen.

diese letztere Methode der Schwefelbestimmung, was ihre Ausführung anlangt, ziemlich mühevoll und zeitraubend ist, wie denn auch der Umstand, dass man völliger Sicherheit halber immer genöthigt ist, den in Salzsäure unlöslichen Rückstand mit salpetersaurem und kohlensaurem Natron zu schmelzen, und die so erhaltene Masse weiter auf Schwefelsäure zu prüfen und diese nöthigenfalls zu bestimmen, abgesehen von der Complication, die das Verfahren hiedurch erleidet, eben nicht zur Verminderung der Fehlerquellen beiträgt. Es schien mir unter diesen Umständen nicht ganz überflüssig, ein einfacheres Verfahren zur Bestimmung des Schwefelgebaltes aufzusuchen, und anlässlich verschiedener Roheisenanalysen, wie sie mir im hierortigen Laboratorium wiederholt vorgekommen sind, hatte ich mehrfach Gelegenheit, diessbezügliche Versuche anzustellen, deren Resultate so günstig waren, dass ich das Verfahren, zu dessen Anwendung sie mich führten, als ein recht brauchbares, der Mittheilung für werth erachte. Mein Verfahren, wie ich es anzuwenden pflege, ist in Kürze folgendes. Ich bringe eine abgewogene, nicht zu geringe Menge des zu prüfenden mässig fein vertheilten Roheisens in einen geräumigen Glaskolben and übergiesse dasselbe mit etwa der 20fachen Menge einer mässig concentrirten, vom Säureüberschuss möglichst befreiten Auflösung von Eisenchlorid, und digerire, während ich dem Kolben eine geneigte Stellung gebe, durch 8-10 Stunden unter mässigem Erwärmen. (Es genügt eine Temperaturerhöhung auf $25-30^{\circ} \mathrm{C}$.)

Unter schwacher Gasentwickelung und unter Bildung ron Eisenchlorür erfolgt in der oben angegebenen Zeit die Lösung der Hauptmenge des Eisens, und es hinterbleibt endlich eine lockere schwarze Masse, welche neben geringen Mengen noch ungelösten freien Eisens, sämmtlichen Graphitkohlenstoff, Schwefel, Phosphor, so wie fast den gesammten Siliciumgehalt des Roheisens enthält. Wird nunmehr dieser, nicht weiter lösliche Antheil auf einem Filter gesammelt, möglichst rasch gewaschen und endlich getrocknet, so hat man ein Material, durch dessen directe Oxydation man leicht, und obne Verlust befürchten zu müssen sämmtlichen Schwefel in Schwefelsäure überführen und als Barytsalz weiter der Wägung zuführen kann. Die Oxydation nehme ich in der Art vor, dass ich die genannte rüclsständige Masse sammt dem Filter in einen Porzellantiegel eintrage, dessen Boden mit einer Schichte eines Gemenges von drei Theilen salpetersaurem Kali und einem Theile Aetzkali, beide selbstverständlich schwefelsäurefrei, überdeckt ist, und nach dem Eintragen des zu oxydirenden Materials dieses weiter mit einer Partie des oxydirenden Gemenges überschichte. 
Der so beschickte Tiegel wird anfangs mässig und erst allmählich stärker erhitzt, und zwar so lange bis eine möglichst vollständige oxydation erreicht ist. Die erhaltene Schmelze, welche nunmehr allen Schwefel als schwefelsaures Salz neben gleichzeitig entstandenem phosphorsaurem, kohlensaurem und kieselsaurem Salze und einer Partie von Eisenoxyd enthält, wird geradeza in Wasser gelöst, die Lösung rom Ungelösten abfiltrirt, und aus dem klaren Filtrate nach dem Ansäuern mit Chlorwasserstoffsäure mittelst Chlorbaryum sämmtliche Schwefelsäure als Barytsalz gefält, und endlich als solches der Wägung unterworfen. Die Resultate dieser Bestimmungsmethode fallen, sofern mit irgend einiger Präcision gearbeitet wird, sehr genau aus, und weichen kaum wesentlich von denjenigen $a b$, welche nach der von $G$. Lippert und und R. Fresenius mit Recht als zuverlässig empfohlenen Methode erbalten werden. . So fand ich in einer Sorte Robeisens bei Bestimmungen nach der G. Lippert'schen Methode, und zwar:

Bei der Bestimmung I. den Schwefelgehalt $=0,197$ Proc.

",$\quad$ II. " $, \quad=0,178$ Proc.

Im Mittel sonach . . . . . . $=0,187$ Proc.

Bei der Bestimmung nach meinem oben erörterten Verfahren, und zwar:

Bei der Bestimmung I. den Schwefelgehalt $=0,201$ Proc.

Im Mittel sonach $\quad$ II. . . . . . . . $=0,195$ Proc.

In einer zweiten Sorte Roheisens fand ich nach der G. Lippert'schen Methode einen Schwefelgehalt von $=0,342$ Proc. Nach meinem Verfahren einen Schwefelgehalt $=0,360$ Proc.

Das Verfahren von J. Nicklés lieferte einen gelb gefärbten schwefelsauren Baryt, dem sich die letzten Reste anhängenden Eisenaxydsalzes nicht völlig entziehen liessen, und aus dessen Menge sich ein Schwefelgehalt von 0,491 Proc. in demselben Roheisen berechnete.

Es ist selbstverständlich, dass sich bei der Anwendung des von mir im Vorgehenden besprochenen Verfahrens mit Leichtigkeit unter einem auch die Bestimmung des Phosphorgehaltes wird ausführen lassen, so wie dass für Fälle, wo es anf hochgradige Genauigkeit nicht ankommt, auch eine Bestimmung des Siliciumgehaltes sich nebenbei oline wesentliche Schwieriglkeit erreichen lassen wird. 